\title{
Statistical wind speed studies and wind energy potential resource analysis of abong mbang, Cameroon: a case study
}

\author{
Yemele David ${ }^{1}$, Bawe Gerard Nfor, Jr *, Talla Pierre Kisito, Ghogomu Patrick Ndinakie \\ Department of Physics, University of Dschang, P. O. Box 67, Dschang, West Region, Cameroon \\ *Corresponding author E-mail: nforbawe@yahoo.com
}

Copyright $\odot 2015$ Yemele David et al. This is an open access article distributed under the Creative Commons Attribution License, which permits unrestricted use, distribution, and reproduction in any medium, provided the original work is properly cited.

\begin{abstract}
Accurate analysis of wind characteristics for a particular site is the first step towards wind energy resource installation. In this study, the onus is to determine the wind energy potential characteristics, and the best representative probability density function, for the Abong Mbang weather station and its immediate environ. The Chi square, coefficient of determination and root mean square error were used as the discriminating goodness of fit tests. Results show that the gamma distribution is the best representative of the wind speed regime, closely followed by the Weibull distribution. We equally study the feasibility of the installation of wind turbine systems at this site based on the Weibull and the Rayleigh models. It is observed that Abong Mbang is characterized by very low wind speeds, higher shape parameters than the scale parameters and consequently very low power density values. Abong Mbang is not technically feasible for the installation of small wind turbine.
\end{abstract}

Keywords: Wind Energy Resource; Power Density; Gamma; Weibull; Cameroon

\section{Introduction}

The most important indicator of the economy of any country is its degree of industrialization, which is driven by energy. Many sources of energy abound. Conventional methods for energy generation such as fossil fuels, hydroelectric and nuclear power have many shortcomings, amongst which are environmental concerns and increasing strict government regulations. Also, depletion, particularly with fossil fuels is of very long term great concern. There is, therefore, need for alternative sources that are renewable and environmentally friendly. The search, discovery, interest and great research have identified some alternative sources, among which are wind, solar, tidal and geothermal, to name a few. Incidentally, they are equally abundant worldwide, albeit specificity in some cases. With increasing technological advances, almost each type and regime can be exploited in varying amounts and specific needs. A second goal of using renewable energy sources is not only for large-scale energy production (grid or microgrid connection), but also for stand-alone systems [1].

Cameroon depends heavily on hydropower and thermal generators for her electricity demand and experiences severe power shortages, especially, during the dry season. Additionally, wider portions of the population are located in very hostile terrain and far off the grid system. Accessibility to more $75 \%$ of the country is very deplorable due to inadequate road infrastructure, particularly during the rainy season.

The fastest developing and most commonly used energy source worldwide is wind energy. Wind energy is a clean and renewable alternative source of energy potential, as opposed to fossils based energy sources polluting the lower layer atmosphere. Because of its desirable characteristics, viz, renewable, abundance and environmental friendliness, systems transforming wind power to electrical energy have been developing quite fast [2]. Wind energy is a form of solar energy; it is air current created by the balance between pressure and temperature differences due to the differential distribution of solar heat coming to Earth. [3] 
Energy is essential to the economic and social development of any country, and will improve the quality of life in Cameroon. Cameroon is a developing country and, comparatively, under-industrialized and plans to be in the near future. Her energy demand has increased, at least, with population and will follow the same pattern with the advent of industrialization. The energy demand situation in various parts of Cameroon is exemplified by frequent outages and low tension. Tchinda and Kaptouom [4], Tchinda et al. [5] studied the energy potential in the northern parts of Cameroon and observed that they were not very viable for electricity generation. However, in the literature, so far, no such study has been carried out in some other parts of the country, including Abong Mbang. It is therefore important to study the suitability, or not, of the installation of aerogenerators in other data available sites, particularly in the hinterlands, so as to curb some of the energy inadequacies. Small scale off grid installations could benefit a small community for small scale applications.

The effective use of wind energy is the conversion of wind power into valuable forms of electricity. One of the preliminary steps in the sitting of a wind power project is the assessment of its site's wind resource. This involves a detailed analysis of the wind speed profile at the proposed installation height, its prevailing direction, turbulence intensity, the shape and scale parameters, the wind distribution, wind power density and class, etc. [6].

The distribution of wind speed is important for power generators. It is therefore necessary to model wind speeds in order to understand their characteristics [7]. Several studies have investigated the modeling of appropriate wind speed distribution. The most popular and successfully representative were the Weibull and the Rayleigh distributions [8]. However, many studies [9-12] have shown that the Weibull and Rayleigh may not be the most appropriate representative of some wind regimes. Brano et al. [10] from among seven different distribution functions, (Weibull, Rayleigh, Lognormal, Gamma, Inverse Gaussian, Pearson type V and Burr), discovered that the Burr distribution was the most acceptable. Jaramillo and Borja [11] showed that the wind regime was bimodal, and further that the Mixed Weibull distribution is more appropriate for bimodal probability density function (PDF) wind regimes than the 2parameter Weibull distribution

In this study, firstly, we determine the most appropriate theoretical probability density function for the Abong Mbang weather station using five different probability density functions. This is followed by using three different goodness of fit, (GOF or gof), tests, namely, the chi square, Coefficient of determination, $\mathrm{R}^{2}$, and root mean square (RMSE). The best agreements are obtained for very low values of X2 and RMSE, whereas it is desirable for R2 to be as close to one as possible to validate closeness and acceptability.

\section{Data and site descriptions}

Wind speed data for the period July 1967 to June 1969, measured at 6m above ground level, was obtained from the Abong Mbang meteorological station. Abong Mbang is situated at $3^{\circ} 5^{\prime} 0^{\prime \prime}$ North, $13^{\circ} 11^{\prime} 0^{\prime \prime}$ East and altitude $700.13 \mathrm{~m}$ above sea level in the East Region and the equatorial zone of the Republic of Cameroon. Inasmuch as in situ wind data at the desirable height, where the turbine is to be installed, is the best for wind energy exploration analysis for final exploitation, measurements at less height can always be extrapolated to desired heights by using the wind shear or power law [13-14], given as:

$\frac{\mathrm{v}_{2}}{\mathrm{v}_{1}}=\left(\frac{\mathrm{h}_{2}}{\mathrm{~h}_{1}}\right)^{\alpha}$

Where $v_{2}$ is the projected wind speed at desired height $h_{2}$ and $v_{1}$ is the wind speed measured at measured height $h_{1}=$ $10 \mathrm{~m} . \alpha$ is a constant that depends on the topography of the site. The average value of $\alpha$ has been determined by many measurements around the world to be about one-seventh. However, rigorous studies have mentioned that, to be more precise, increasing heights, time and season, nature of the terrain, weather effect, etc, may not be neglected [15].

\section{Methodology}

In this section we briefly describe different competing probability models considered in this study and mention the estimation procedures of their unknown parameters from the data set and determination of other relevant secondary parameters.

The description of the behavior of wind speed of a particular site requires the identification of the distribution that best fits the data; discriminated by using different goodness of fit (gof) tests. In this study we model the wind speed distribution by using the Gamma, Weibull, Rayleigh, Normal and Lognormal probability distribution functions. Their cumulative probability functions are also mentioned. The gofs considered are the Chi-Squared (CS), R2 and the RMSE tests.

\subsection{Weibull distribution}

The Weibull probability function is given by equation (2): 
$f(v)=\left(\frac{k}{c}\right)\left(\frac{v}{c}\right)^{k-1} \exp \left[-\frac{v^{k}}{c}\right]$

Where $\mathrm{f}(\mathrm{v})$ is the probability of the measured wind speed, $\mathrm{v}$, and $\mathrm{k}$ and $\mathrm{c}$ are the shape and scale parameters, respectively. The speed and scale parameters are measured in $\mathrm{m} / \mathrm{s}$ whereas the shape parameter is dimensionless.

The average wind speed can be represented by:

$\overline{\mathrm{v}}=\int_{0}^{\infty} \mathrm{vf}(\mathrm{v}) \mathrm{dv}=\int_{0}^{\infty}\left(\frac{\mathrm{vk}}{\mathrm{c}}\left[\left(\frac{\mathrm{v}}{\mathrm{c}}\right)^{\mathrm{k}-1}\right] \exp \left[\left(\frac{\mathrm{v}}{\mathrm{c}}\right)^{\mathrm{k}}\right]\right) \mathrm{dv}$

Evaluating the various mathematical transformations on equations (2) and (3) as provided in [16], we finally obtain equations (4) and (5) for the mean wind speed and standard deviation, respectively, by:

$\overline{\mathrm{v}}=\mathrm{c} \Gamma\left(1+\frac{1}{\mathrm{k}}\right)$

$\sigma=\mathrm{c}\left[\Gamma\left(1+\frac{2}{\mathrm{k}}\right)-\Gamma^{2}\left(1+\frac{1}{\mathrm{k}}\right)\right]^{1 / 2}$

where $\Gamma($.$) is the gamma function.$

The cumulative density function, $\mathrm{CDF}$, is determined as:

$\mathrm{F}(\mathrm{v})=1-\exp \left[-\frac{\mathrm{v}^{\mathrm{k}}}{\mathrm{c}}\right]$

Maximum likelihood estimation procedure for the 2-parameter Weibull function in equation (7) [17] has been an extensively used method for estimating the parameters of the Weibull distribution due to its desirable properties. The commonly used procedure to determine $\mathrm{k}$ is the Newton-Raphson routine:

$\frac{\sum_{i=1}^{n} x_{i}^{k_{j}} \ln x_{i}}{\sum_{i=1}^{n} x_{i}^{k_{j}}}-\frac{1}{k_{j}}-\frac{1}{n} \sum_{i=1}^{n} \ln x_{i}=0$

Once $\mathrm{k}$ is determined, $\mathrm{c}$ can be estimated from:

$\mathrm{c}=\frac{\sum_{\mathrm{i}=1}^{\mathrm{n}} \mathrm{x}_{\mathrm{i}}^{\mathrm{k}}}{\mathrm{n}}$

Where $\mathrm{n}$ is the length of data.

\subsection{Raleigh distribution}

Maseran et al. [18] give the Rayleigh distribution as a special case of the Weibull where the shape factor $\mathrm{k}$ is set to 2; its PDF and CDF are determined by equations (9) and (10), respectively.

$f(x)=\frac{x}{b^{2}} \exp \left(-\frac{1}{2}\left(\frac{x}{b}\right)^{2}\right)$

$\mathrm{F}(\mathrm{x})=1-\exp \left(-\frac{1}{2}\left(\frac{\mathrm{x}}{\mathrm{b}}\right)^{2}\right)$

The Rayleigh distribution arises when wind velocity has elements that are normally distributed and are uncorrelated [19].

\subsection{Gamma distribution}

A positive random variable $\mathrm{X}$ is said to be gamma $(\mathrm{a}, \mathrm{b})$ distributed when it has the probability density

$\mathrm{f}(\mathrm{x} \mid \mathrm{a}, \mathrm{b})=\frac{1}{\mathrm{~b}^{\mathrm{a}} \Gamma(\mathrm{a})} \mathrm{x}^{\mathrm{a}-1} \exp \left(-\frac{\mathrm{x}}{\mathrm{b}}\right) ; \mathrm{x} \geq 0, \mathrm{a}>0, b>0$

and CDF is by, 
$\mathrm{F}(\mathrm{x})=1-\sum_{\mathrm{k}=1}^{\mathrm{a}-1} \frac{\left(\frac{\mathrm{x}}{\mathrm{b}}\right)^{\mathrm{k}} \exp \left(-\frac{\mathrm{x}}{\mathrm{b}}\right)}{\mathrm{k} !}$

where $\mathrm{a}$ and $\mathrm{b}$ are the shape and scale parameters, respectively. [20]]

In the literature, [21-24], the most popular method for the estimation the gamma of parameters is that of moments because of its simplicity. The parameters are estimated by solving the following two equations (13) and (14):

$\mathrm{E}(\mathrm{x})=\mathrm{ab}$

$\operatorname{Var}(\mathrm{x})=\mathrm{ab}^{2}$

where $\mathrm{E}($.$) represents the estimation of, and \operatorname{Var}($.$) the variance, of the variable. In this work, we, however, use [25] in$ equations (14a15) and (14b16):

$\overline{\mathrm{x}}=\mathrm{ab}$

$\mathrm{a}=\left(\frac{\overline{\mathrm{x}}}{\mathrm{s}(\mathrm{x})}\right)^{2}-\frac{1}{\mathrm{n}}$

where $\overline{\mathrm{x}}$ is the mean, $\mathrm{s}(\mathrm{x})$ the standard deviation and $\mathrm{n}$ the data length. Direct observations show that (16) is less than (14). It is observed that the reciprocal of $\mathrm{n}$ is approximately 0.3 for monthly data, whose percentage error, of at least $3 \%$, may not be so insignificant. However, for yearly data length or more, equation (14) may be directly used with insignificant error.

\subsection{Lognormal distribution}

The lognormal [26], [27] is a special form of the normal distribution where the logarithm of the variable is normally distributed. The distribution function, expected value and variance, respectively, are defined by equations (17), (18) and (19).

$f(x)=\frac{1}{x \sigma \sqrt{2 \pi}} \exp \left(-\frac{1}{2}\left(\frac{x^{\prime}-\mu}{\sigma}\right)^{2}\right)$

$E(X)=e^{\mu+\frac{\sigma}{2}}$

$\operatorname{Var}(X)=\mathrm{e}^{2 \mu+\sigma^{2}}\left(\mathrm{e}^{\sigma^{2}}-1\right)$

\section{Wind power density}

The available power density, Pw, obtainable directly from the data set is given by [28]

$\mathrm{P}_{\mathrm{w}}=\frac{1}{2} \rho \overline{\mathrm{v}^{3}}$

Where $\rho$ is the density of the air. That determined based on a theoretical density function is:

$P_{m}=\frac{1}{2} \rho \int v^{3} f_{m}(v) d v$

Where $\mathrm{f}_{\mathrm{m}}$ denotes model density function. When the Weibull PDF is considered [15], evaluation of $\mathrm{f}_{\mathrm{m}}$ gives the mean power, Pm, as in equations (22) and (23).

$\mathrm{P}_{\mathrm{m}}=\frac{1}{2} \rho \overline{\mathrm{v}^{3}} \frac{\Gamma\left(1+\frac{3}{\mathrm{k}}\right)}{\Gamma^{3}\left(1+\frac{1}{\mathrm{k}}\right)}$

Or $\mathrm{P}_{\mathrm{m}}=\frac{1}{2} \rho c^{3} \Gamma\left(1+\frac{3}{\mathrm{k}}\right)$

where $\mathrm{k}$ and $\mathrm{c}$ are the Weibull shape and scale parameters, respectively. 


\section{5. discriminating procedures: GOF tests}

In order to deduce the degree of convergence of the various distributions to the actual measured data, the following three tests were performed on each of the probability distribution functions.

\subsection{The coefficient of determination (COD or R2)}

$\mathrm{R}^{2}$, as given in [29], is one of the foremost probability distribution discriminators and hypothesis testing because it quantifies the correlation between observed and predicted probabilities and is given by:

$\mathrm{R}^{2}=1-\frac{\sum_{\mathrm{i}=1}^{\mathrm{N}}\left(\mathrm{X}_{\mathrm{i}}-\mathrm{x}_{\mathrm{i}}\right)^{2}}{\sum_{\mathrm{i}=1}^{\mathrm{N}}\left(\mathrm{X}_{\mathrm{i}}-\overline{\mathrm{X}}\right)^{2}}$

A large value of $\mathrm{R}^{2}$ indicates a better fit of the model.

\subsection{The root mean square error}

The root mean square error is given by [30] as:

$\operatorname{RMSE}=\sqrt{\frac{1}{\mathrm{~N}} \sum_{\mathrm{i}=1}^{\mathrm{N}}\left(\mathrm{X}_{\mathrm{i}}-\mathrm{x}_{\mathrm{i}}\right)^{2}}$

Where $\mathrm{X}_{\mathrm{i}}, \mathrm{X}_{\mathrm{i}}$ and $\overline{\mathrm{X}}$ in equations (24) and (25) are the observed, estimated and mean of the data, respectively.

\subsection{The minimum chi square method}

This is the oldest method which is being used for goodness of fit or model discrimination and validation. The ChiSquare method is used for testing the predicted against the actual wind distribution. The least determined value, among the distributions, on this model, normally chooses it as the best probability representative candidate. The Chi-square $\chi^{2}$ is given by [31]:

$\chi^{2}=\sum \frac{\sum_{\mathrm{i}}^{\mathrm{k}}\left(\mathrm{O}_{\mathrm{i}}-\mathrm{E}_{\mathrm{i}}\right)^{2}}{\mathrm{E}_{\mathrm{i}}}$

where $\mathrm{Oi}, \mathrm{Ei}$ and $\mathrm{k}$ are the observed, expected frequencies and $\mathrm{k}$ the number of bins.

The least value of RMSE and $\chi^{2}$ indicates a better fit of the model.

\section{Results and discussions}

\subsection{Results}

Wind speed data obtained from the Abong Mbang weather station was used in evaluating different PDFs to assess that which best represents the wind regime at this base and the capability of its wind energy potential. Self-written codes using Matlab R2013b were used for all computational work. The most suitability PDF is determined by using goodnessof-fit tests.

Tables 1 and 2 Summarize the monthly numerical results for all distributions' parameters and the gof tests for the two years; July 1967 to June 1968 and July 1968 to June 1969, respectively. Following the discriminating criteria or gofs, it is observed from these tables that for the Abong Mbang weather station, the distribution function that best describes the wind pattern at this site is the gamma distribution. It is closely followed, value wise, by the Weibull distribution. Thus, inasmuch as the results discriminate in favour of gamma as the best representative, Weibull could also be used without the loss of generality in describing the wind regime at this site. The shape parameters are generally greater than the scale parameters; varying from 2.2 to 5.6 and the scale parameters from $1.7 \mathrm{~m} / \mathrm{s}$ to $2.6 \mathrm{~m} / \mathrm{s}$, respectively. 
Table 1: Summary of Numerical Results for the Parameters and Gofs for Various Probability Distributions

\begin{tabular}{|c|c|c|c|c|c|c|c|c|c|c|c|}
\hline \multirow{2}{*}{ Month } & \multirow{2}{*}{ PDF } & \multicolumn{5}{|c|}{ July - December 1967} & \multicolumn{5}{|c|}{ January - June 1968} \\
\hline & & $\mathrm{k}$ & $\mathrm{c}$ & Rmse & $\mathrm{R} 2$ & $\mathrm{x} 2$ & $\mathrm{k}$ & $\mathrm{c}$ & Rmse & R2 & $\mathrm{x} 2$ \\
\hline \multirow{5}{*}{ Jul/Jan } & Weibull & 4.4 & 2.6 & 0.047 & 0.9931 & 0.0046 & 5.4 & 1.9 & 0.094 & 0.9773 & 0.0158 \\
\hline & Rayleigh & 2 & 1.7 & 0.136 & 0.9458 & 0.0385 & 2 & 1.3 & 0.159 & 0.935 & 0.0452 \\
\hline & Gamma & 14.1 & 0.2 & 0.043 & 0.9944 & 0.0038 & 26.1 & 0.1 & 0.08 & 0.9841 & 0.0113 \\
\hline & Normal & 2.3 & 0.6 & 0.044 & 0.9458 & 0.004 & 1.8 & 0.3 & 0.089 & 0.935 & 0.0141 \\
\hline & LogNormal & 0.8 & 0.3 & 0.054 & 0.9458 & 0.0061 & 0.6 & 0.2 & 0.078 & 0.935 & 0.0107 \\
\hline \multirow{5}{*}{ Aug/Feb } & Weibull & 2.6 & 2.3 & 0.043 & 0.9942 & 0.0038 & 4.2 & 2.4 & 0.059 & 0.987 & 0.0078 \\
\hline & Rayleigh & 2 & 1.6 & 0.05 & 0.9925 & 0.0051 & 2 & 1.6 & 0.127 & 0.9489 & 0.0357 \\
\hline & Gamma & 5.5 & 0.4 & 0.047 & 0.9934 & 0.0045 & 14.1 & 0.2 & 0.046 & 0.9926 & 0.0047 \\
\hline & Normal & 2.1 & 0.9 & 0.045 & 0.9925 & 0.0042 & 2.2 & 0.6 & 0.055 & 0.9489 & 0.0067 \\
\hline & LogNormal & 0.6 & 0.5 & 0.062 & 0.9925 & 0.0079 & 0.7 & 0.3 & 0.042 & 0.9489 & 0.004 \\
\hline \multirow{5}{*}{ Sep/Mar } & Weibull & 3.8 & 2.2 & 0.061 & 0.9873 & 0.008 & 5.6 & 2.7 & 0.07 & 0.9832 & 0.0104 \\
\hline & Rayleigh & 2 & 1.4 & 0.113 & 0.9603 & 0.0277 & 2 & 1.8 & 0.155 & 0.9274 & 0.0518 \\
\hline & Gamma & 11.4 & 0.2 & 0.048 & 0.9924 & 0.005 & 23.2 & 0.1 & 0.059 & 0.9885 & 0.0074 \\
\hline & Normal & 1.9 & 0.6 & 0.058 & 0.9603 & 0.0074 & 2.5 & 0.5 & 0.064 & 0.9274 & 0.0088 \\
\hline & LogNormal & 0.6 & 0.3 & 0.045 & 0.9603 & 0.0044 & 0.9 & 0.2 & 0.056 & 0.9274 & 0.0067 \\
\hline \multirow{5}{*}{ Oct/Apr } & Weibull & 3.8 & 2.3 & 0.054 & 0.9926 & 0.0053 & 3.1 & 2.1 & 0.081 & 0.9811 & 0.0126 \\
\hline & Rayleigh & 2 & 1.5 & 0.102 & 0.9739 & 0.0189 & 2 & 1.4 & 0.1 & 0.9731 & 0.0191 \\
\hline & Gamma & 11.8 & 0.2 & 0.042 & 0.9957 & 0.0031 & 8.4 & 0.2 & 0.062 & 0.989 & 0.0075 \\
\hline & Normal & 2.1 & 0.6 & 0.052 & 0.9739 & 0.005 & 1.9 & 0.6 & 0.084 & 0.9731 & 0.0137 \\
\hline & LogNormal & 0.7 & 0.3 & 0.039 & 0.9739 & 0.0027 & 0.6 & 0.3 & 0.055 & 0.9731 & 0.0059 \\
\hline \multirow{5}{*}{ Nov/May } & Weibull & 4.1 & 2.4 & 0.07 & 0.9866 & 0.0093 & 4.4 & 2.2 & 0.086 & 0.9799 & 0.013 \\
\hline & Rayleigh & 2 & 1.6 & 0.13 & 0.9562 & 0.0318 & 2 & 1.5 & 0.116 & 0.9658 & 0.0236 \\
\hline & Gamma & 13.8 & 0.2 & 0.056 & 0.9916 & 0.0059 & 16.9 & 0.1 & 0.071 & 0.987 & 0.0089 \\
\hline & Normal & 2.1 & 0.6 & 0.068 & 0.9562 & 0.0088 & 2 & 0.5 & 0.084 & 0.9658 & 0.0123 \\
\hline & LogNormal & 0.7 & 0.3 & 0.053 & 0.9562 & 0.0053 & 0.7 & 0.2 & 0.069 & 0.9658 & 0.0084 \\
\hline \multirow{5}{*}{ Dec/June } & Weibull & 3.1 & 1.9 & 0.095 & 0.9686 & 0.0206 & 3.9 & 2.3 & 0.056 & 0.99 & 0.0068 \\
\hline & Rayleigh & 2 & 1.3 & 0.13 & 0.9473 & 0.0382 & 2 & 1.6 & 0.117 & 0.9594 & 0.0291 \\
\hline & Gamma & 8.7 & 0.2 & 0.084 & 0.9763 & 0.0159 & 11.7 & 0.2 & 0.047 & 0.9932 & 0.0047 \\
\hline & Normal & 1.7 & 0.6 & 0.093 & 0.9473 & 0.0198 & 2.1 & 0.6 & 0.054 & 0.9594 & 0.0063 \\
\hline & LogNormal & 0.5 & 0.4 & 0.091 & 0.9473 & 0.019 & 0.7 & 0.3 & 0.05 & 0.9594 & 0.0053 \\
\hline
\end{tabular}

Table 2: Summary of Numerical Results for the Parameters and Gofs for Various Probability Distributions

\begin{tabular}{|c|c|c|c|c|c|c|c|c|c|c|c|}
\hline \multirow{2}{*}{ Month } & \multirow{2}{*}{ PDF } & \multicolumn{5}{|c|}{ July 1968 - December 1968} & \multicolumn{5}{|c|}{ January 1969 - June 1969} \\
\hline & & $\mathrm{k}$ & $\mathrm{c}$ & Rmse & $\mathrm{R} 2$ & $\mathrm{x} 2$ & $\mathrm{k}$ & $\mathrm{c}$ & Rmse & $\mathrm{R} 2$ & $\mathrm{x} 2$ \\
\hline \multirow{5}{*}{ Jul/Jan } & Weibull & 3.8 & 2.3 & 0.064 & 0.9889 & 0.0074 & 3.3 & 1.5 & 0.053 & 0.9916 & 0.0056 \\
\hline & Rayleigh & 2 & 1.5 & 0.088 & 0.9801 & 0.014 & 2 & 1 & 0.077 & 0.9828 & 0.012 \\
\hline & Gamma & 11.3 & 0.2 & 0.055 & 0.9919 & 0.0056 & 8.3 & 0.2 & 0.052 & 0.9918 & 0.0056 \\
\hline & Normal & 2.1 & 0.6 & 0.063 & 0.9801 & 0.0071 & 1.3 & 0.5 & 0.053 & 0.9828 & 0.0057 \\
\hline & LogNormal & 0.7 & 0.3 & 0.053 & 0.9801 & 0.0051 & 0.2 & 0.4 & 0.06 & 0.9828 & 0.0073 \\
\hline \multirow{5}{*}{ Aug/Feb } & Weibull & 5.2 & 2 & 0.063 & 0.988 & 0.008 & 4.5 & 2.3 & 0.082 & 0.9789 & 0.0136 \\
\hline & Rayleigh & 2 & 1.3 & 0.165 & 0.9222 & 0.0552 & 2 & 1.5 & 0.154 & 0.9336 & 0.0478 \\
\hline & Gamma & 21.1 & 0.1 & 0.056 & 0.9908 & 0.0063 & 18.4 & 0.1 & 0.065 & 0.987 & 0.0086 \\
\hline & Normal & 1.9 & 0.4 & 0.059 & 0.9222 & 0.007 & 2.1 & 0.5 & 0.077 & 0.9336 & 0.0122 \\
\hline & LogNormal & 0.6 & 0.2 & 0.057 & 0.9222 & 0.0066 & 0.7 & 0.2 & 0.061 & 0.9336 & 0.0076 \\
\hline \multirow{5}{*}{ Sep/Mar } & Weibull & 3.2 & 1.9 & 0.072 & 0.9841 & 0.0104 & 3.8 & 2 & 0.065 & 0.9864 & 0.0087 \\
\hline & Rayleigh & 2 & 1.3 & 0.102 & 0.9704 & 0.021 & 2 & 1.3 & 0.126 & 0.9535 & 0.0325 \\
\hline & Gamma & 8.8 & 0.2 & 0.056 & 0.9908 & 0.0062 & 12.7 & 0.1 & 0.05 & 0.9922 & 0.0052 \\
\hline & Normal & 1.7 & 0.6 & 0.074 & 0.9704 & 0.011 & 1.8 & 0.5 & 0.062 & 0.9535 & 0.0079 \\
\hline & LogNormal & 0.5 & 0.3 & 0.051 & 0.9704 & 0.0051 & 0.6 & 0.3 & 0.048 & 0.9535 & 0.0047 \\
\hline \multirow{5}{*}{ Oct/Apr } & Weibull & 3.2 & 2.2 & 0.05 & 0.9935 & 0.0045 & 4.6 & 2 & 0.059 & 0.9878 & 0.0075 \\
\hline & Rayleigh & 2 & 1.4 & 0.057 & 0.9916 & 0.006 & 2 & 1.3 & 0.136 & 0.9433 & 0.0397 \\
\hline & Gamma & 8 & 0.2 & 0.042 & 0.9954 & 0.0033 & 16 & 0.1 & 0.051 & 0.9914 & 0.0056 \\
\hline & Normal & 1.9 & 0.7 & 0.054 & 0.9916 & 0.0053 & 1.8 & 0.5 & 0.055 & 0.9433 & 0.0066 \\
\hline & LogNormal & 0.6 & 0.5 & 0.048 & 0.9916 & 0.0042 & 0.6 & 0.3 & 0.051 & 0.9433 & 0.0056 \\
\hline \multirow{5}{*}{ Nov/May } & Weibull & 3.3 & 1.7 & 0.078 & 0.9818 & 0.012 & 4.4 & 2.1 & 0.064 & 0.9859 & 0.0089 \\
\hline & Rayleigh & 2 & 1.1 & 0.107 & 0.9679 & 0.0229 & 2 & 1.4 & 0.159 & 0.9245 & 0.0547 \\
\hline & Gamma & 9.3 & 0.2 & 0.065 & 0.9877 & 0.0084 & 16.9 & 0.1 & 0.055 & 0.9901 & 0.0066 \\
\hline & Normal & 1.5 & 0.5 & 0.078 & 0.9679 & 0.0122 & 1.9 & 0.5 & 0.059 & 0.9245 & 0.0076 \\
\hline & LogNormal & 0.4 & 0.3 & 0.062 & 0.9679 & 0.0076 & 0.6 & 0.3 & 0.06 & 0.9245 & 0.0078 \\
\hline \multirow{5}{*}{ Dec/June } & Weibull & 2.2 & 1.7 & 0.122 & 0.9585 & 0.0263 & 3.8 & 2.3 & 0.063 & 0.989 & 0.0074 \\
\hline & Rayleigh & 2 & 1.1 & 0.121 & 0.9606 & 0.0259 & 2 & 1.6 & 0.125 & 0.9592 & 0.0296 \\
\hline & Gamma & 4.6 & 0.3 & 0.103 & 0.9711 & 0.0189 & 12.8 & 0.2 & 0.052 & 0.9928 & 0.005 \\
\hline & Normal & 1.5 & 0.7 & 0.132 & 0.9606 & 0.0311 & 2.1 & 0.6 & 0.061 & 0.9592 & 0.0069 \\
\hline & LogNormal & 0.3 & 0.4 & 0.08 & 0.9606 & 0.0115 & 0.7 & 0.3 & 0.05 & 0.9592 & 0.0048 \\
\hline
\end{tabular}


Table 3 is a summary of the monthly mean wind speeds for the two years. The mean wind speeds for the first and second years were found to be between $2.3 \mathrm{~m} / \mathrm{s}$ and $2.1 \mathrm{~m} / \mathrm{s}$, respectively. It observed that the mean wind speeds are generally low and ranging from $1.7 \mathrm{~m} / \mathrm{s}$ to $2.3 \mathrm{~m} / \mathrm{s}$, and from $1.7 \mathrm{~m} / \mathrm{s}$ to $2.1 \mathrm{~m} / \mathrm{s}$ for the first and second years, respectively.

Table 3: Monthly Mean Wind Speed for 2 Years, Each

\begin{tabular}{llllllllllllll}
\hline Month & Jul & Aug & Sept & Oct & Nov & Dec & Jan & Feb & Mar & Apr & May & Jun & Annual \\
\hline $1967-1968$ & 2.3 & 2.1 & 1.9 & 2.1 & 2.1 & 1.7 & 1.8 & 2.2 & 2.5 & 1.9 & 2.0 & 2.1 & 2.3 \\
$1968-1969$ & 2.1 & 1.9 & 1.7 & 1.9 & 1.5 & 1.5 & 1.3 & 2.1 & 1.8 & 1.8 & 1.9 & 2.1 & 2.1 \\
\hline
\end{tabular}

Figures 1, 2, 3 show the wind speed histograms of the frequency distribution for all the distributions spanning two years, the first year and the second years, respectively. The curves obtained using the numerical values of the determined parameters are superposed on the wind speed histograms. The normal, gamma and Weibull, in each of the histograms follow the shape of histogram. However, on close examination, it is observed that, particularly to the left (lowest wind speed) and right (highest wind speed) of the middle (highest concentration of frequencies), the normal curve always deviates from the bars more than for gamma and the Weibull curves. Closely following the general shape of the histogram and touching the histogram bars are the Weibull and gamma models. The Rayleigh underestimates the data while the lognormal does better but without capturing very well the high wind speeds. The same figures also show high frequencies of low wind speeds in the middle of the histogram. For the CDFs of Figs. 4, 5 and 6, respectively, it is observed that the Rayleigh distribution does not well represent the data, but there is very close competing (tightness) for the others, as already mentioned above.

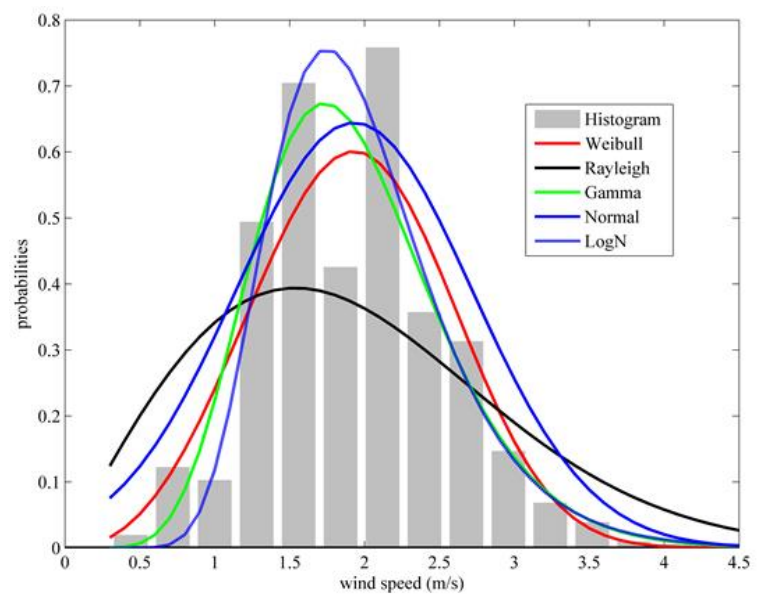

Fig. 1: PDFs for Abong Mbang for the 2 Years

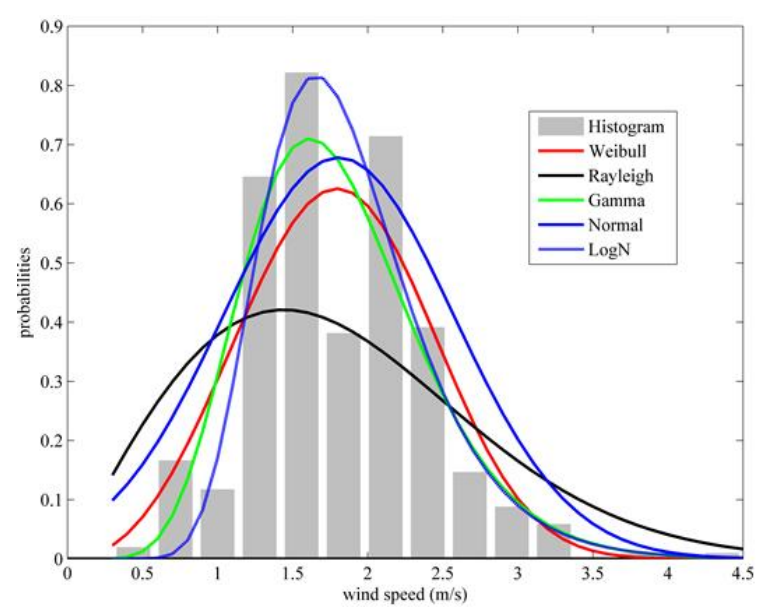

Fig. 3: PDFs for Abong Mbang for the Second Year

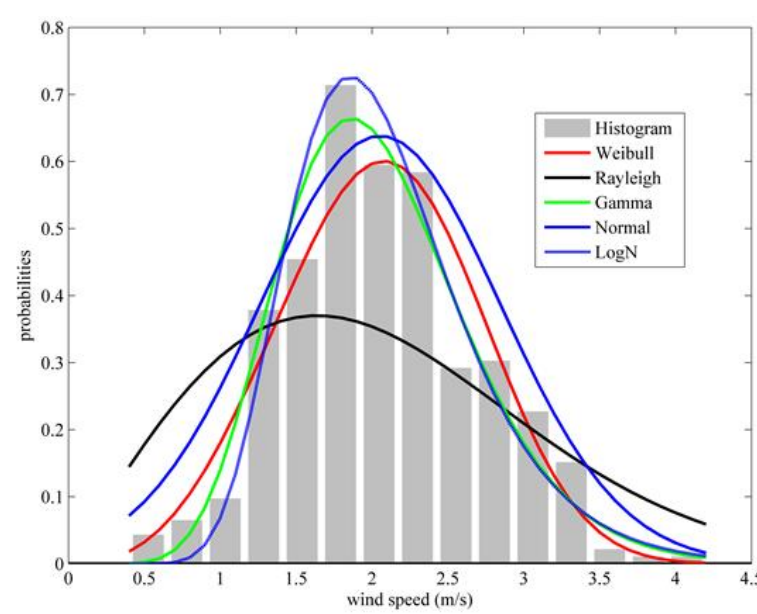

Fig. 2: PDFs for Abong Mbang for the First Year

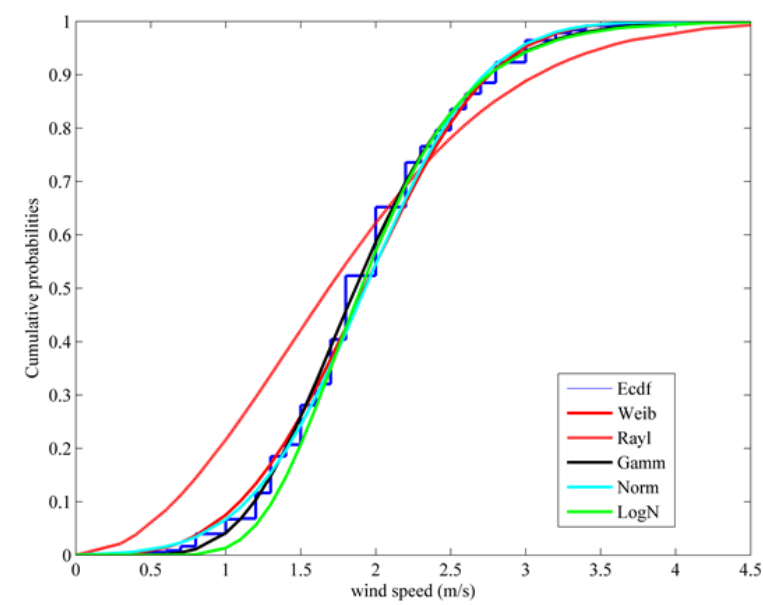

Fig. 4: ECDF and CDFs for Abong Mbang for the 2 Year 


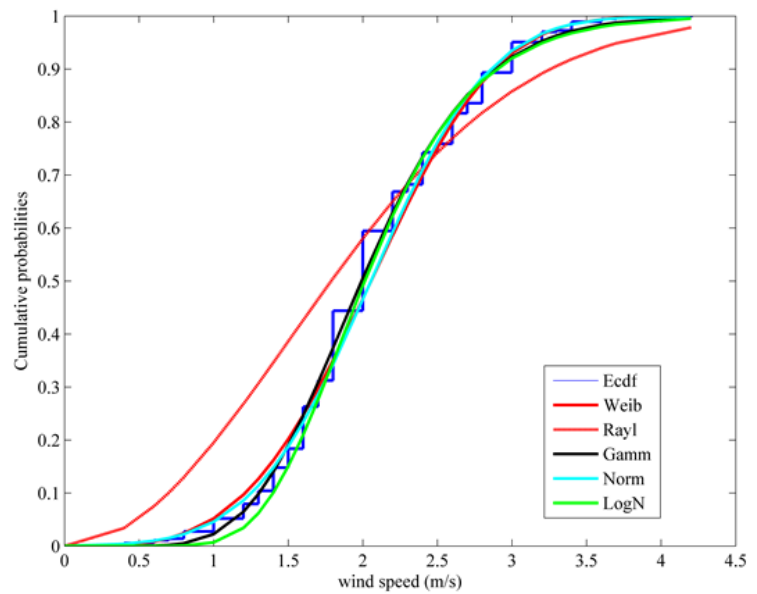

Fig. 5: ECDF and CDFs for Abong Mbang for the First Year

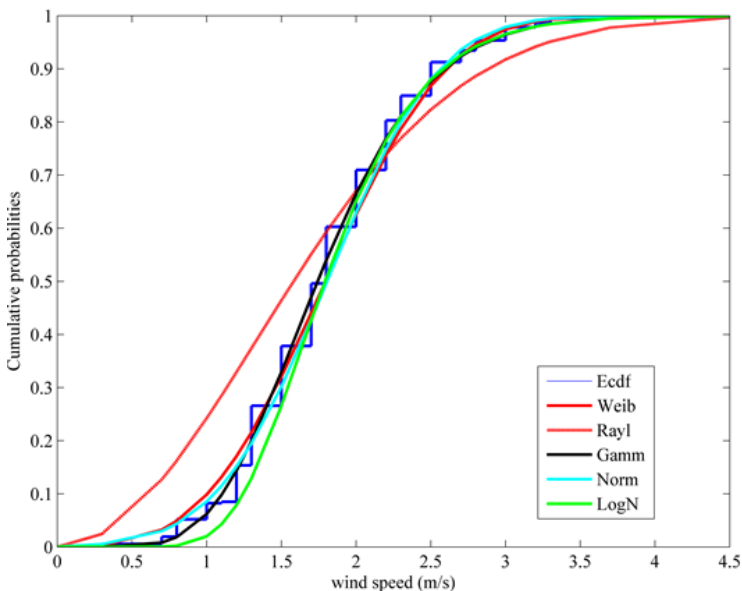

Fig. 6: ECDF and CDFs for Abong Mbang for the Second Year

Tables 4 and 5 present, respectively, the monthly and annual summaries of the numerically determined values of the power density based on the theoretical, Weibull and Rayleigh models while Table 5 shows the annual average power density for each year and for the composite two years.

Table 4: Monthly Power Densities for Each Year (W/M²)

\begin{tabular}{|c|c|c|c|c|c|c|c|c|c|c|c|c|c|}
\hline Year & PDF & July & Aug & Sep & Oct & Nov & Dec & Jan & Feb & Mar & Apr & May & June \\
\hline \multirow{3}{*}{$67-68$} & Theoretical & 8.65 & 7.6 & 5.2 & 6.2 & 6.7 & 3.7 & 3.6 & 7.0 & 9.5 & 5.0 & 5.4 & 6.6 \\
\hline & Weibull & 8.6 & 7.7 & 5.2 & 6.2 & 6.8 & 3.7 & 3.6 & 7.0 & 9.6 & 5.1 & 5.5 & 6.6 \\
\hline & Rayleigh & 13.8 & 9.5 & 7.9 & 9.4 & 10.6 & 5.1 & 6.1 & 11.0 & 16.2 & 7.0 & 8.8 & 10.2 \\
\hline \multirow{3}{*}{$68-69$} & Theoretical & 6.0 & 4.1 & 4.0 & 5.5 & 2.6 & 3.4 & 1.8 & 6.0 & 4.1 & 4.0 & 4.7 & 6.7 \\
\hline & Weibull & 6.0 & 4.2 & 4.0 & 5.6 & 2.7 & 3.1 & 1.8 & 6.1 & 4.2 & 4.0 & 4.8 & 6.8 \\
\hline & Rayleigh & 9.1 & 7.0 & 5.7 & 7.8 & 3.8 & 3.4 & 2.6 & 9.9 & 6.3 & 6.5 & 7.7 & 10.3 \\
\hline
\end{tabular}

Table 5: Annual and Two-Year Power Densities (W/M²)

\begin{tabular}{llll}
\hline Period & Theoretical & Weibull & Rayleigh \\
\hline $1967-1968$ & 6.3 & 6.3 & 9.3 \\
$1968-1969$ & 4.4 & 4.7 & 6.3 \\
$1967-1969$ & 5.3 & 5.4 & 7.7 \\
\hline
\end{tabular}

The power densities are generally very low and lower for the second year; as a consequence of the lower wind speeds observed during this period. For the first year, the power densities range from 3.6 to $9.5 \mathrm{~W} / \mathrm{m}^{2}, 3.6$ to $9.6 \mathrm{~W} / \mathrm{m}^{2}$ and 5.1 to $16.2 \mathrm{~W} / \mathrm{m}^{2}$, respectively, for the theoretical, Weibull and Rayleigh. During the second year, they range from 1.8 to $6.7 \mathrm{~W} / \mathrm{m}^{2}, 1.8$ to $6.8 \mathrm{~W} / \mathrm{m}^{2}$ and 2.6 to $10.3 \mathrm{~W} / \mathrm{m}^{2}$, respectively, for the theoretical, Weibull and Rayleigh. The Rayleigh model is always higher than the Weibull. The annual rated theoretical power densities are 6.3 and $4.4 \mathrm{~W} / \mathrm{m}^{2}$ for first and second years, respectively; while for the Weibull and Rayleigh models, they are 6.3 and $4.7 \mathrm{~W} / \mathrm{m}^{2}$, and 9.3 and 6.3 $\mathrm{W} / \mathrm{m}^{2}$, pair-wise, respectively, for the first and second years. For the two-year period, they are $5.3,5.4$ and $7.7 \mathrm{~W} / \mathrm{m}^{2}$, respectively, for the theoretical Weibull and Rayleigh power density models.

\subsection{Conclusion}

In this study, we determined the most descriptive probability density function for wind regime for the Abong Mbang weather station based on data spanning two years and its wind energy potential. It was observed that the best candidate was the gamma distribution function, followed very closely by the Weibull pdf. Considering the very low values observed for the wind density, Abong Mbang weather station is not technically feasible for the installation of even small wind turbines. Given low frequency (daily) and limited period of data (only two years) used in this study, it is advisable to revisit this site sometime in the future after having accumulated a much longer duration of data and at higher heights for very valid assessment, particularly with respect to the dominant wind speed regime because the best representative PDF may be different at the same site for different heights [27].

\section{Acknowledgement}

We wish to acknowledge the contributions of Mr. Megam Elie Bertrand and Dr. Kenfack Kevin Sadem with some Matlab programs used for simulations in this work. 


\section{References}

[1] W. Zhou, C. Lou, Z. Li, L. Lu and H. Yang, Current status of research on optimum sizing of stand-alone hybrid solar-wind power generation systems, Applied Energy, 87(2) (2010) 380-9 http://dx.doi.org/10.1016/j.apenergy.2009.08.012.

[2] H. ARAS, V. YILMAZ and H.E. ÇELIK, Estimation of Monthly Wind Speeds of Eskişehir, Turkey. The First International Exergy, Energy and Environment Symposium, Hotel Princess, Izmir, Turkey, (July 2003) 13-17.

[3] V. YILMAZ and H. E. ÇELIK, Doğuș Üniversitesi Dergisi, A Statistical Approach to Estimate the Wind Speed Distribution: The Case of Gelibolu Region, 9 (1), (2008) 122-132.

[4] R. Tchinda and E. Kaptouom, Wind energy in Adamaoua and North Cameroon provinces, Int J Energy Conver Manag (44) (2003) 845-57

[5] R. Tchinda, J. Kendjio, E. Kaptouom and D. Njomo, Estimation of mean wind energy available in far north Cameroon, Energy Conversion and Management, Pergamon, (41) (2000) 1917-1929.

[6] Z. O. Olaofe and K. A. Folly, Statistical Analysis of the Wind Resources at Darling for Energy Production, International Journal of Renewable Energy Research, (2012) Vol.2, No.2.

[7] K. Abbas, Alamgir, Sajjad Ahmad Khan, Amjad Ali, Dost Muhammad Khan and Umair Khalil, Statistical Analysis of Wind Speed Data in Pakistan, World Applied Sciences Journal, 18 (11) (2012) 1533-1539, ISSN 1818-4952.

[8] S. Mathew, Wind Energy: Fundamentals, Resource Analysis and Economics, Springer-Verlag, Berlin Heidelberg 2006. http://dx.doi.org/10.1007/3-540-30906-3.

[9] J. A. Carta and P. Ramirez, Analysis of two-component mixture Weibull statistics for estimation of wind speed distribution. Renew. Energ. (32) (2007) 518-531.

[10] V. L. Brano, A. Orioli, G. Ciulla and S. Culotta, Quality of wind speed fitting for urban area of Palermo, Italy, Renew. Energ. (36) (2011) 1026-1039.

[11] O. A. Jaramillo and M. A. Borja, Wind speed analysis in La Ventosa, Mexico: a bimodal probability distribution case, Renew. Energ. (29) (2004) 1613-1630.

[12] B. Safari, "Modeling wind speed and wind power distribution in Rwanda. Renew. Sust. Energy Rev. (15) (2011) 925-935.

[13] E. K. Akpinar and S. Akpinar, An assessment on seasonal analysis of wind energy characteristics and wind turbine characteristics, Energy Conversion and Management (46) (2005) 1848-1867 http://dx.doi.org/10.1016/j.enconman.2004.08.012.

[14] I. A. Perez, M. A. Garcia, M. L. Sanchez and Torre de B., Analysis of height variations of sodar-derived wind speeds in Northern Spain, Journal of Wind Engineering and Industrial Aerodynamics (92) (2004) 875-894.

[15] G. Johnson, Wind Energy Systems, Kansas State University, Manhattan, KS, USA, 2006.

[16] P. Bhattaracharya and R. Bhattacharjee, "Journal of Applied Quantitative Methods" Vol 5 No. 2 (Summer 2010).

[17] 1. A. K. Azad, M. G. Rasul and T. Yusaf; Statistical Diagnosis of the Best Weibull Methods for Wind Power Assessment for Agricultural Applications, Energies (7) (2014) 3056-3085.

[18] N. Masseran, A. Mahir Razali, K. Ibrahim, A. Zaharim and K. Sopian, The Probability Distribution Model of Wind Speed over East Malaysia, Research Journal of Applied Sciences, Engineering and Technology 6(10) (2013) 1774-1779

[19] R. Gupta and A. Biswas, Wind analysis of silchar (Assam, India) by Rayleigh's and Weibull methods, Journal of Mechanical Engineering Research Vol. 2(1) (February 2010) 010-024.

[20] E. L. Silva and P. Lisboa, "Analysis of the characteristic features of the density functions for gamma, Weibull and log-normal distributions through RBF network pruning with QLP", Proceedings of the 6th WSEAS Int. Conf. on Artificial Intelligence, Knowledge Engineering and Data Bases, Corfu Island, Greece (February 2007)16-19.

[21] H. Aksoy, Use of gamma distribution in Hydrological analysis, Turk J Engin Environ Sci (24) (2000) 419-428.

[22] D. P. Wiens, J. Cheng and N. C. Beaulieu, "Pak. J. Statist" Vol.19 (1) (2003) 129-141.

[23] P-H. Huang and T-Y. Hwang, "On New Moment Estimation of Parameters of the Generalized Gamma Distribution using its Characterization", Taiwanese Journal Of Mathematics, Vol. 10 No. 4 (June 2006) 1083-1093.

[24] C. Forbes, M. Evans, N. Hastings and B. Peacock, Statistical Distributions, John Wiley and Sons, Inc, (2011) 4th Edition.

[25] T. Y. Hwang and P. H. Huang, On new moment estimation of parameters of the gamma distribution using its characterization, Annals of the Institute of Statistics Mathematics (54) (2002) 840-847, Japan http://dx.doi.org/10.1023/A:1022471620446.

[26] M. A. Hussain, M. J. Iqbal and S. Soomro, Urban Wind Speed Analysis in Global Climate Perspective: Karachi as a Case Study, Internal Journal of Geosciences (3) (2012) 1000-1009.

[27] Y. Hou, Y. Peng, A. L. Johnson and J. Shi, Empirical Analysis of Wind Power Potential at Multiple Heights for North Dakota Wind Observation Sites, CS Canada, Energy Science and TechnologyVol4 No. 1 (2012) 1-9.

[28] R. Kollu1, S. R. Rayapudi, S.V.L. Narasimham and K. M. Pakkurthi, Mixture probability distribution functions to model wind speed distributions, International Journal of Energy and Environmental Engineering, (2012) 3-27.

[29] C. Carillo, J. Cidras, E. Diaz-Dorado and A. F. Obando-Montano, An approach to determine the Weibull Parameters for wind Energy Analysis: The Case of Galicia (Spain), Energies (7) (2014) 2676-2700.

[30] O. O. Ajayi, R.O. Fagbenle, J. Katende, O.A. Omotosho and Samson Aasa, Analytical Predictive Model for Wind Energy Potential Estimation: A Model for Pre-assessment Study, Journal of Applied Sciences 12(5) (2012) 450-458 http://dx.doi.org/10.3923/jas.2012.450.458.

[31] K. Abbas, Alamgir, S. A. Khan, A. Ali, D. M. Khan and U. Khalil, Statistical Analysis of Wind Speed Data in Pakistan, World Applied Sciences Journal 18 (11) (2012) 1533-1539. 